\title{
Metode Ta'dib dan Komunikasi Islami Menurut Perspektif Al-Qur'an dan Hadist dalam Pembangunan Karakter Anak Usia Dini
}

\section{Ta'dib Method and Islamic Communication According To Perspective of Qur'an and Hadith in Development Of Character of Early Childhood}

\author{
HERLINA HUSEN \\ STIKes Mitra Kencana, Jl. RE. Martadinata no. 142, \\ Kode Pos 46133, Tasikmalaya, Indonesia \\ Email: herlinahusen2014@gmail.com
}

\begin{abstract}
Parents are responsible for the education of their children. Child character education should be done at an early age. The Qur'an and Sunnah of the Prophet Muhammad Sallallahu 'Alayhi Wassalam are the two main sources of reference to a Muslim in solving all his problems, including children's education. If revealed, there are many stories of Prophets and People in the Qur'an and Hadith, which can be used as a guide by parents in educating children. Among them are Islamic ta'dib method and Islami communication. Ta'dib combines teaching and instills an understanding of the cognitive aspects as well as commands and restrictions in the affective aspect. While Islamic communication refers to six types of words in the Qur'an such as Qaulan Sadiidan, Qaulan baligha, Qaulan ma'rufa, Qaulan Kariima, Qaulan layyina, and Qaulan maisura. Islamic Ta'dib and Islamic communication can support the success of parents in building the character of early childhood when practiced appropriately and accompanied by prayer.
\end{abstract}

Keywords: Ta'dib, Communication, Children's Education, and Early Age.

\begin{abstract}
Abstrak
Orangtua adalah penanggungjawab bagi pendidikan anak-anaknya. Hendaknya pendidikan karakter anak dilakukan pada usia dini. Al Qur'an dan Sunnah Nabi Muhammad Salallahu 'alaihi Wassalam merupakan 2 sumber utama yang menjadi rujukan seorang muslim dalam menyelesaikan segala problematikanya, termasuk pendidikan anak. Jika diturunkan, banyak sekali kisah para Nabi dan Orang-orang sholeh dalam Al Quran maupun hadist, yang dapat dijadikan pedoman oleh orangtua dalam mendidik anak. Diantaranya adalah metode ta'dib islami dan komunikasi islami. Ta'dib memadukan pengajaran dan menanamkan pemahaman dalam aspek kognitif serta perintah dan larangan dalam aspek afektif. Sementara komunikasi Islami merujuk pada enam jenis perkataan didalam Al Qur'an diantaranya Qaulan Sadiidan, Qaulan baligha, Qaulan ma'rufa, Qaulan Kariima, Qaulan layyina, dan Qaulan maisura. Ta'dib islami dan komunikasi islami dapat menunjang keberhasilan orangtua dalam membangun karakter anak usia dini jika dipraktekan secara tepat dan disertai do'a.
\end{abstract}

Kata Kunci: Ta'dib, Komunikasi, Pendidikan Anak, dan Usia Dini.

\section{Pendahuluan}

Anak adalah amanah yang diberikan Allah kepada setiap orangtua. Pada hari kiamat kelak Allah akan meminta pertanggungjawaban orangtua akan kewajibannya kepada anak. Meliputi tanggung jawab nafkah, pendidikan, perlindungan, kesehatan dan lain sebagainya.
Demikian pentingnya amanah ini, sehingga Allah mengingatkan orangtua agar sungguhsungguh dalam mengamalkannya.

Allah Swt. berfirman:

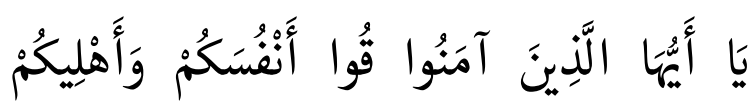




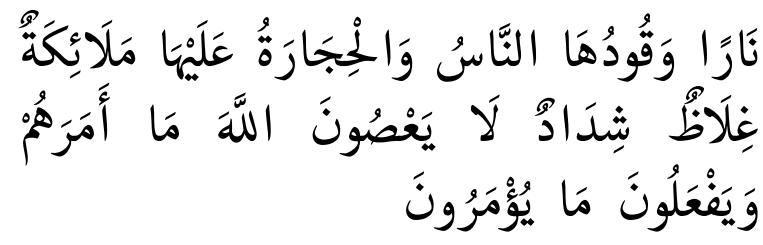

"Hai orang-orang yang beriman, peliharalah dirimu dan keluargamu dari api neraka yang bahan bakarnya adalah manusia dan batu; penjaganya malaikat-malaikat yang kasar, keras, dan tidak mendurhakai Allah terhadap apa yang diperintahkan-Nya kepada mereka dan selalu mengerjakan apa yang diperintahkan" (QS. At-Tahrim: 6).

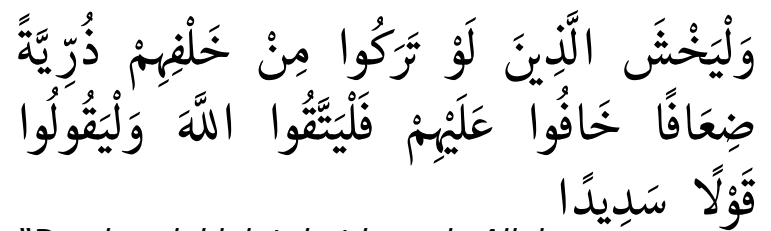

"Dan hendaklah takut kepada Allah orang-orang yang seandainya meninggalkan dibelakang mereka anak-anak yang lemah, yang mereka khawatir terhadap (kesejahteraan) mereka. Oleh sebab itu hendaklah mereka bertakwa kepada Allah dan hendaklah mereka mengucapkan perkataan yang benar" (QS. An-Nisa: 9).

Orangtua bertanggung jawab untuk mengantarkan anak memasuki gerbang syurga dan menghindarkannya dari neraka dengan mendidiknya. Hal ini dikemukakan oleh Al-Ghozali yang dikutip oleh Ahmad Tafsir, "ketahuilah, bahwa melatih jiwa anakanak termasuk hal yang amat penting dan perlu. Anak-anak adalah amanat ditangan kedua orang tuanya. Jiwanya (hatinya) yang masih suci bagaikan batu permata yang masih polos belum diukir dan belum dibentuk. Karena itu, dengan mudah saja ia menerima segala bentuk rekayasa yang ditujukan kepadanya, dan memiliki kecenderungan yang dibiasakan kepadanya. Jika baik, ia akan tumbuh dewasa dalam keadaan baik dan bahagia, dalam kehidupan di dunia maupun di akhirat. Kedua orang tuanya, guru serta pendidiknyapun ikut pula menerima pahala yang disediakan baginya. Tetapi sebaliknya, jika dibiasakan kepadanya perbuatan yang buruk atau diterlantarkan seperti halnya hewan yang berkeliaran tak menentu, niscaya ia akan sengsara dan binasa. Dosanya akan dipikul juga oleh orang tuanya, walinya, atau siapa saja yang bertanggung jawab atas pendidikannya" (Tafsir Ahmad, 1992).

Demikian pentingnya pendidikan anak, sehingga seharusnya sudah dimulai sejak anak berada dalam kandungan, ketika Allah sudah meniupkan ruh dan menciptakan pendengaran pada janin didalamnya. Kemudian dilanjutkan ketika anak telah lahir ke dunia. Para ahli menyatakan bahwa usia 0-6 tahun adalah masa keemasan (golden age). Di fase usia ini, anak mengalami pertumbuhan dan perkembangan yang pesat. Menurut banyak penelitian bidang neurologi ditemukan bahwa $50 \%$ kecerdasan anak terbentuk pada kurun waktu 4 tahun pertama. Setelah usia 8 tahun, perkembangan otaknya mencapai $80 \%$ dan pada usia 18 tahun mencapai $100 \%$ (Suyanto, 2005).

Pada fase ini pula pembentukan karakter anak dimulai. Dimana, karakter yang telah tertanam sejak kecil inilah yang akan terus melekat dan terbawa hingga ia dewasa.

Untuk menunjang keberhasilan orangtua dalam pendidikan tersebut, maka sudah semestinya orangtua merujuk pada dua sumber dalil syariat, yaitu Al Qur'an dan Hadist. Karena kedua sumber ini adalah tuntunan sempurna bagi segala problematika manusia. Dari kedua sumber ini dapat diturunkan metodologi pendidikan anak yang dibutuhkan.

Di dalam Al Qur'an terdapat setidaknya tiga istilah yang digunakan untuk menerangkan konsep pendidikan, yaitu tarbiyah dengan kata kerja rabba ,ta'lim dengan kata kerja 'allama dan ta'dib dengan kata kerja addaba.

Ta'dib adalah salah satu istilah yang dipakai dalam dunia pendidikan Islam selain dari tarbiyah, ta'lim dan lainlainnya. Ta'dib, tarbiyah dan ta'lim bila ditinjau dari sisi bahasa, sama-sama mempunyai arti pendidikan, yang dalam bahasa Inggris nya diistilahkan education. Akan tetapi, tadib lebih mewakili istilah pendidikan islam. Sebab ta'dib sudah mencakup unsurunsur ilmu ('ilmu), instruksi (ta'lim), dan pembinaan yang baik (tarbiyah) (Rambe Imron, 2012).

Tadib adalah perpaduan semua unsur pendidikan mulai dari menanamkan pemahaman yang sebelumnya tidak dipahami anak, memunculkan kesadaran untuk beramal, pendampingan, pembiasaan dan pemaksaan dalam tuntutan pelaksanaan kewajiban, hingga hukuman jika terdapat pelanggaran. Sehingga tadib membutuhkan pengajaran dalam aspek kognitif serta perintah/ajakan dan larangan dalam aspek afektif.

Disinilah orangtua perlu memahami metode ta'dib dan komunikasi efektif yang dicontohkan dalam kisah-kisah Nabi dan orang-orang sholeh didalam Al-Quran serta diteladankan Nabi Muhammad SAW. Karena metode tadib dan tehnik komunikasi saling 
berkaitan dan tidak bisa dipisahkan satu sama lain. Metode yang baik, tanpa komunikasi yang tepat tidak akan mengantarkan pada tujuan pendidikan yang diharapkan.

\section{Pembahasan}

\section{Konsep Ta'dib}

Tadib merupakan bentuk masdar dari kata addaba-yuaddibu-ta'diban, yang artinya mengajarkan sopan santun. Sedangkan menurut istilah ta'dib diartikan sebagai proses mendidik yang di fokuskan kepada pembinaan dan penyempurnaan akhlak. Fokus pembahasan ta'dib berorientasi pada kesadaran dan pemahaman ilmu yang benar dalam diri seseorang agar menghasilkan kemantapan amal dan tingkah laku yang baik. Sabda Nabi saw:

$$
\text { أدبنى ربن فأحسن تأدبى }
$$

"Tuhanku telah mendidikku, dan dengan demikian menjadikan pendidikanku yang terbaik"

Rasulullah SAW meneladankan kepada kita, bagaimana metode tadib pada anak.

\section{Menanamkan Tauhid dan kecintaan kepada Allah}

عن بن عباس قال كنت خلف رسول

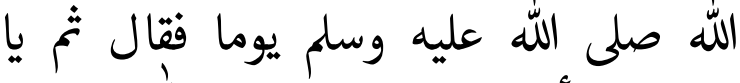
غلام إني أعلمك كلمات احفظ الله يكفظك اله

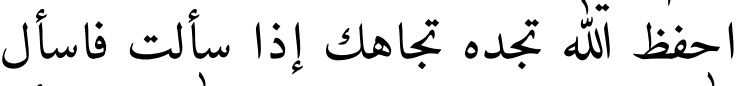

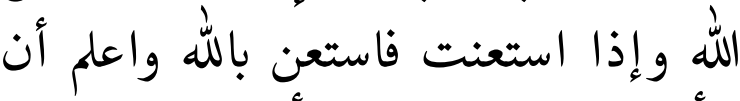

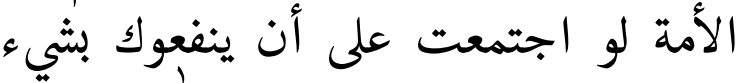
لم ينفعوك إلا بثيء قد كتبه الله لك الك ولو

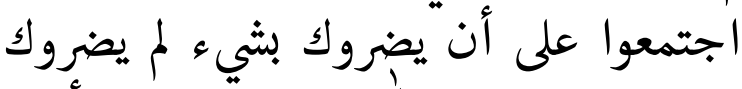
إلا بشيء قد كتبه الله عليك رفعت الأقلام وجفت الصحفيء الصغ . رواه أحمد والترمذي

"Dari sahabat Ibnu Abbas ia berkata: Suatu hari aku membonceng Nabi shollallahu 'alaihi wa sallam, maka beliau bersabda kepadaku: 'Wahai nak, sesungguhnya aku akan ajarkan kepadamu beberapa kalimat: Jagalah (syariat) Allah, niscaya Allah akan menjagamu, jagalah (syariat) Allah, niscaya engkau akan dapatkan (pertolongan/perlindungan) Allah senantiasa di hadapanmu. Bila engkau meminta (sesuatu) maka mintalah kepada Allah, bila engkau memohon pertolongan, maka mohonlah pertolongan kepada Allah. Ketahuilah (yakinilah) bahwa umat manusia seandainya bersekongkol untuk memberimu suatu manfaat, niscaya mereka tidak akan dapat memberimu manfaat melainkan dengan sesuatu yang telah Allah tuliskan untukmu, dan seandainya mereka bersekongkol untuk mencelakakanmu, niscaya mereka tidak akan mampu mencelakakanmu selain dengan suatu hal yang telah Allah tuliskan atasmu. Al Qalam (pencatat takdir) telah diangkat, dan lembaran-lembaran telah kering. "' (Riwayat Ahmad, dan At Tirmizy)

Percakapan Rasulullah SAW dengan Abdullah bin abas (anak sepupunya) menggambarkan pentingnya penanaman tauhid sebagai pondasi dasar bagi anak dalam mengarungi kehidupan. Dalam hadist tersebut, Rasulullah mengajarkan Abdullah bin abbas agar beriman dengan keimanan yang murni, senantiasa bergantung hanya kepada Allah, dan menjaga syariatNya sebagai bukti keimanan kepadaNya.

\section{Nasehat berupa perintah dan laran- gan}

أخذ الحسن بن علي رضي الله عنهما تمرة من تمر الصدقة فجعلها في فيه فقال النبي

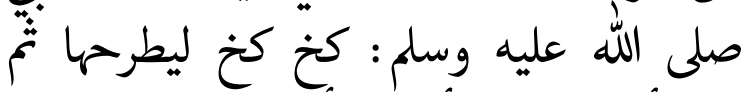

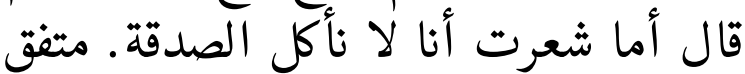
عليه "Al Hasan bin Ali rodhiallahu 'anhuma mengam̈bil sebiji kurma dari kurma shadaqah (zakat), kemudian ia memasukkannya ke dalam mulut (hendak memakannya) maka Nabi shollallahu 'alaihi wa sallam bersabda kepadanya: 'Kakh, kakh,' agar ia mencampakkannya, kemudian beliau bersabda kepadanya, 'Tidakkah engkau sadar bahwa kita tidak (halal) memakan shadaqah?'" (Muttafaqun 'alaih)

Hadits ini menjadi panduan dalam pendidikan anak. Dimana Rasululloh telah menanamkan prinsip-prinsip agama terkait halal dan haram sejak usia Cucunya Al Hasan masih sangat kecil.

Secara khusus berkenaan dengan shalat, maka Nabi shallallahu 'alaihi wa sallam telah bersabda:

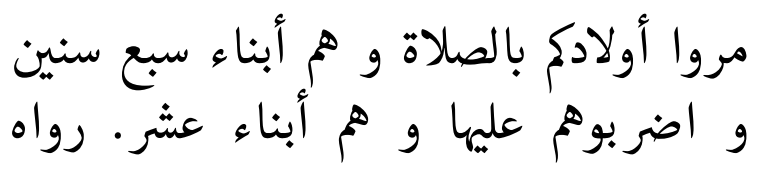




$$
\text { أحمد وأبو داود والحاكج }
$$

"Perintahlah anak-anakmu agar mendirikan shalat tatkala mereka telah berumur tujuh tahun, dan pukullah karenanya tatkala mereka telah berumur sepuluh tahun."

Pada hadits ini Nabi shallallahu 'alaihi wa sallam dengan tegas mensyariatkan agar pendidikan shalat dimulai sejak dini, yakni sebelum baligh. Sekalipun perintah sholat kepada anak disyariatkan saat berusia tujuh tahun, namun syariat ini tentu membutuhkan persiapan. Yaitu dengan mengajarkan tata cara wudhu, tatacara dan bacaan sholat, membiasakan sholat lima waktu, menerangkan hal-hal yang membatalkan sholat dan lain sebagainya. Sehingga di usia tujuh tahun anak relatif lebih mudah melaksanakan karena sudah terbiasa. Dan di usia sepuluh tahun, anak tidak perlu sering diberikan hukuman, karena proses pembiasaan sholat sudah lama dilakukan sejak usia dini.

\section{Membiasakan adab yang baik}

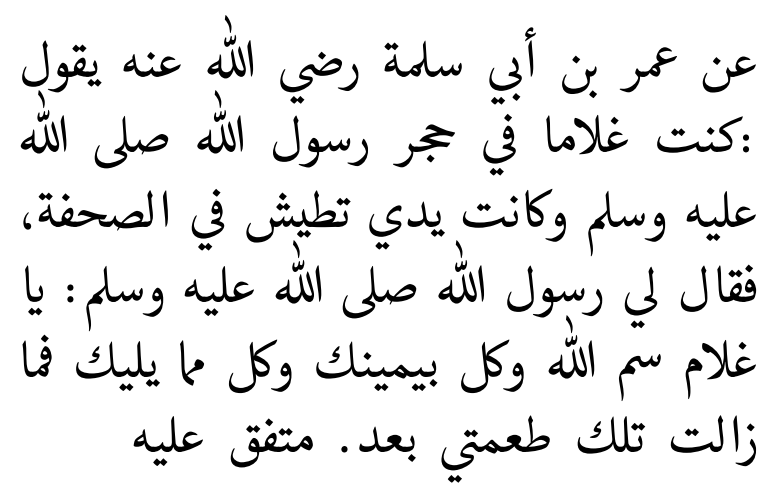

"Dari sahabat Umar bin Abi Salamah radhiallahu 'anhu, ia mengisahkan: Dahulu ketika aku masih kecil dan menjadi anak tiri Rasulullah shallallahu 'alaihi wa sallam, dan (bila sedang makan) tanganku (aku) julurkan ke segala sisi piring, maka Rasulullah shallallahu 'alaihi wa sallam bersabda, 'Hai nak, bacalah bismillah, dan makanlah dengan tangan kananmu, dan makanlah dari sisi yang terdekat darimu.' Maka semenjak itu, itulah etikaku ketika aku makan." (Muttafaqun 'alaih).

\section{Teladan yang baik dan pendampin- gan}

Rasulullah Salallahu 'alaihi Wassalam adalah teladan terbaik. Ketika beliau memerintahkan sesuatu, beliau telah menerapkan terlebih dahulu pada dirinya. Beliau adalah pribadi istimewa, hingga perkataannya didengar dan amalnya diikuti.
Anak-anak yang hidup dan mendapat bimbingan langsung Nabi sangat mengidolakan Nabi SAW, sehingga mereka mudah dididik. Ini adalah hal asasi yang harus diperhatikan oleh orangtua. Yakni bagaimana menjadikan dirinya sebagai orang yang paling dikagumi anak. Orangtualah orang terdekat yang menyenangkan dan menjadi role model bagi anak. Dengan demikian, pendidikan dan pengasuhan anak akan lebih mudah dilakukan.

\section{Hukuman Bertahap}

Menghukum anak bukanlah hal yang dilarang dalam ta'dib islam. Hukuman terhadap anak dibenarkan dalam pembiasaan adab yang baik dan pelaksanaan kewajiban. Manakala orangtua mendapati anak tidak patuh pada syariat dan menampilkan adab yang buruk, maka orangtua wajib memberi peringatan hingga hukuman yang tepat. Hukuman dalam ta'dib Islam bertujuan untuk mendidik anak-anak agar mereka takut melakukan hal-hal yang tercela.

Rasulullah shallallahu 'alaihi wa sallam menganjurkan ini dalam sabda beliau shallallahu 'alaihi wa sallam, "Gantungkanlah cambuk (alat pemukul) di tempat yang terlihat oleh penghuni rumah, karena itu merupakan pendidikan bagi mereka."

Perintah Rasulullah menggantungkan cambuk tidak dimaksudkan untuk memukul anggota keluarga, akan tetapi dimaksudkan agar anggota keluarga takut terhadap ancaman tersebut dan termotivasi untuk meninggalkan perbuatan buruk dan tercela

Hukuman hendaknya dilakukan secara bertahap, Mulai dari peringatan disertai ketegasan, peringatan kedua disertai muka masam (tidak suka), hukuman ringan hingga sedang jika melanggar adab baik, dan hukuman berat berupa pukulan untuk pelanggaran kewajiban semisal sholat atau puasa, jika anak tersebut telah mencapai usia yang memungkinkannya untuk mengambil pelajaran dari pukulan tersebut,biasanya di usia sepuluh tahun.

Islam memiliki rambu-rambu dalam menghukum anak. Yakni tidak memberi hukuman yang dapat mencelakakan anak. Seperti memukul anak dibawah usia 10 tahun, memukul wajah, memukul terlalu keras yang menimbulkan bekas, dan memukul dalam keadaan sangat marah 


\section{Konsep Komunikasi}

Komunikasi diartikan sebagai proses penyampaian pesan oleh seseorang kepada orang lain untuk memberitahu, mengubah sikap, pendapat, atau perilaku, baik secara lisan (langsung) ataupun tidak langsung (melalui media) (Daftar Definisi Komunikasi (http:// Wikipedia.org/wiki) diunduh pada 26 Desember 2017).

Didalam Al Qur'an, setidaknya terdapat 6 istilah dari lafazh "Qaulan" (perkataan) yang menjadi panduan bagi seorang muslim dalam berkomunikasi. Diantaranya: (1) Qaulan Sadida (QS. An-Nisa:9); (2) Qaulan Baligha ( QS. An-Nisa': 63); (3) Qaulan Ma'rufa ( QS. Al-Baqarah: 235; QS. An- Nisa': 5\& 8; QS. AlAhzab: 32); (4) Qaulan Karima ( QS. Al-Isra': 23); (5) Qaulan Layina ( QS. Thaha: 44); (6) Qaulan Maisura ( QS. Al-Isra': 28) (Prinsip Komunikasi Islam (http:// www.risalah islam. com) diunduh pada 26 Desember 2017)

Keenam jenis perkataan ini bermuara pada prinsip komunikasi dalam Islam yang terdapat dalam ayat:

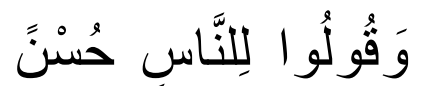

"Dan berkatalah kamu kepada semua manusia dengan cara yang baik (husna)" (QS. AlBaqarah: 83).

\section{Qaulan Sadida (Ucapan yang Benar)}

"Dan hendaklah takut kepada Allah orang-orang yang seandainya meninggalkan dibelakang mereka anak-anak yang lemah, yang mereka khawatir terhadap (kesejahteraan) mereka. Oleh sebab itu hendaklah mereka bertakwa kepada Allah dan hendaklah mereka mengucapkan Qaulan Sadida -perkataan yang benar" (QS. An-Nisa: 9).

Dalam Tafsir Al-Qurtubi dijelaskan, assadid yaitu: perkataan yang bijaksana dan benar.

Benar artinya jujur, tidak dusta, tidak menutup-nutupi atau merekayasa.. "Dan jauhilah perkataan-perkataan dusta" (QS. AlHajj: 30). "Katakanlah kebenaran walaupun pahit rasanya" (HR Ibnu Hibban).

\section{Qaulan Baligha (Berdampak dan Efektif)}

"Mereka itu adalah orang-orang yang Allah mengetahui apa yang di dalam hati mereka. karena itu berpalinglah kamu dari mereka, dan berilah mereka pelajaran, dan katakanlah kepada mereka QaulanBaligha
- perkataan yang berbekas pada jiwa mereka." (QS An-Nissa: 63).

Imam Ibnu Katsir menyatakan makna Qaulan baligha yakni menasihati dengan ungkapan yang menyentuh sehingga mereka berhenti dari perbuatan salah yang selama ini mereka lakukan.

Kata baligh berarti fasih, jelas maknanya, terang, serta tepat dalam mengungkapkan apa yang dimaksud. Komunikasi agar fasih dan jelas maknanya, maka harus disesuaikan dengan kadar intelektualitas orang yang diajak bicara dan menggunakan bahasa yang mudah dimengerti oleh mereka. "Berbicaralah kepada manusia sesuai dengan kadar akal (intelektualitas) mereka" (H.R. Muslim).

"Tidak kami utus seorang rasul kecuali ia harus menjelaskan dengann bahasa kaumnya" (QS. Ibrahim:4)

\section{Qaulan Ma'rufa (Ucapan yang Baik)}

"Dan janganlah kamu serahkan kepada orang-orang yang belum sempurna akalnya, harta (mereka yang ada dalam kekuasaanmu) yang dijadikan Allah sebagai pokok kehidupan. berilah mereka belanja dan pakaian (dari hasil harta itu) dan ucapkanlah kepada mereka Qaulan Ma'rufa -kata-kata yang baik." (QS An-Nissa :5)

"Qulan Ma'rufa -perkataan yang baik- dan pemberian maaf lebih baik dari sedekah yang diiringi dengan sesuatu yang menyakitkan (perasaan si penerima). Allah Maha Kaya lagi Maha Penyantun." (QS. AlBaqarah: 263).

"Hai istri-istri Nabi, kamu sekalian tidaklah seperti wanita yang lain, jika kamu bertakwa. Maka janganlah kamu tunduk dalam berbicara sehingga berkeinginanlah orang yang ada penyakit dalam hatinya] dan ucapkanlah Qaulan Ma'rufa -perkataan yang baik." (QS. Al-Ahzab: 32).

Al-Buruswi menyebutkan qaulan ma'rufa sebagai ungkapan bahasa yang baik dan halus sedangkan Assidiqi menyebutnya sebagai perkataan yang baik, yaitu kata-kata yang tidak membuat orang lain atau dirinya merasa malu.[6] Dapat disimpulkan, bahwa Qaulan Ma'rufa adalah penuturan yang baik, halus, menyenangkan, penuh penghargaan dan tidak menyakiti atau membuat malu orang yang mendengarnya (Qoulan Sadida dalam 
HERLINA HUSEN, Metode Ta'dib dan Komunikasi Islami Menurut Perspektif Al-Qur'an dan Hadist dalam...

Al Qur'an (http:// el-Syahida.blogspot.co.id) Diunduh pada 26 Desember 2017).

\section{Qaulan Karima (Ucapan yang Mulia)}

"Dan Tuhanmu telah memerintahkan supaya kamu jangan menyembah selain Dia dan hendaklah kamu berbuat baik pada kedua orangtuamu dengan sebaik-baiknya. Jika salah seorang di antara keduanya atau kedua duanya sampai berumur lanjut dalam pemeliharaanmu, seklai kali janganlah kamu mengatakan kepada kedanya perkatan 'ah' dan kamu janganlah membentak mereka dan ucapkanlah kepada mereka Qaulan Karima -ucapan yang mulia" (QS. Al-Isra: 23).

Imam Ibnu Katsir (1999) menjelaskan bahwa qaulan karima artinya lembut, baik, dan sopan disertai tata krama, penghormatan dan pengagungan.

Qaulan karima adalah perkataan yang santun dan memuliakan orang yang diajak bicara. Jenis komunikasi ini dikhususkan ketika bicara dengan orang yang lebih tua seperti orangtua dan guru.

\section{Qulan Layina - Lemah-Lembut}

"Maka berbicaralah kamu berdua kepadanya dengan Qulan Layina -kata-kata yang lemah-lembut..." (QS. Thaha: 44).

Imam Ibnu Katsir menyebut qaulan layyina sebagai ucapan yang lemah lembut.

Berkomunikasi dengan cara yang lemah lembut, tidak kasar dan menggunakan bahasa sindiran (bukan makna sebenarnya, khususnya ketika menasehati akan lebih mudah diterima oleh orang yang diajak bicara.

\section{Qaulan Maysura (Mudah Dipahami)}

"Dan jika kamu berpaling dari mereka untuk memperoleh rahmat dari Tuhannya yang kamu harapkan, maka katakanlah kepada mereka Qaulan Maysura-ucapan yang mudah" (QS. Al-Isra: 28).

Qaulan Maysura (Maisuran) bermakna ucapan yang mudah, yakni mudah dicerna, mudah dimengerti, dan dipahami.

Keenam jenis komunikasi yang telah disebutkan diatas ternyata adalah cara berkomunikasi yang dipraktekan oleh para Nabi dan orang-orang sholeh didalam Al-
Quran ataupun diteladankan Nabi Muhammad SAW yang terdapat dalam Al- Hadist.

Lukman Al Hakim adalah seorang tokoh istimewa dalam pendidikan anak, yang patut menjadi teladan bagi para orangtua dalam mendidik anaknya. Bahkan namanya ditahbiskan menjadi salah satu nama surat dalam Al Qur'an.

Pertama Lukman mengajarkan kepada orangtua bagaimana berkata benar (qaulan syadiidan) kepada anak.

Ayat-ayat larangan disampaikan dengan tegas menggunakan lafaz nahyi "Jangan" atau "Tidak". Tidak ada kompromi dan disertai argumentasi

" Dan ingatlah ketika luqman berkata kepada anaknya, di waktu ia memberi pelajaran kepada anaknya: "hai anakku, janganlah kamu mensekutukan Allah, sesungguhnya mempersekutukan Allah adalah benar-benar kedzaliman yang besar. "(QS.Luqman: 13)

Demikian pula Ayat-ayat perintah disampaikan dengan ajakan untuk melaksanakan disertai penjelasan yang menyentuh jiwa

" Dan kami perintahkan kepada manusia(berbuat baik) kepada kedua ibu bapaknya, ibunya telah mengandungnya dalam keadaan lemah yang beertambahtambah, dan menyapihnya dalam dua tahun".(QS.Luqman:14)

"Hai anakku, dirikanlah sholat dan suruhlah(manusia) mengerjakan yang baik dan cegahlah mereka dari perbuatan yang mungkar dan bersabarlah terhadap apa yang menimpamu.sesungguhnya yang demikian itu termasuk hal-hal yang di wajibkan(oleh Allah)". (QS.Luqman: 17)

Ketika mengajarkan akhlak pada anaknya, Lukman menggunakan qaulan baligho (ungkapan yang menyentuh jiwa) dan qaulan layina (Lembut) dengan disertai perumpamaan

"dan janganlah kamu memalinglan mukamu dari manusia (karena sombong) dan janganlah kamu berjalan di muka bumi dengan angkuh.sesungguhnya Allah tidak menyukai orang-orang yang sombong lagi membanggakan diri dan sederhanakanlah kamu dalam berjalan dan Iunakkanlah suaramu.sesungguhnya seburuk-buruknya suara adalah suara keledai". (QS, Luqman: 18-19) 
Teladan Lukman Al-hakim dalam berkomunikasi dengan anak adalah pelajaran berharga bagi para orangtua. Diperlukan komunikasi yang tepat, untuk kondisi yang berbeda. Contoh, ketika orangtua hendak memahamkan anak terkait perintah dan larangan, maka tanamkan dulu akidah dengan ungkapan yang berpengaruh pada jiwa anak. Pilih kosakata yang mudah dicerna anak dengan qaulan syadidan (perkataan yang benar). Gambarkan sifat-sifat Allah yang Maha Pengasih dan penyayang, Allah satusatunya Tuhan yang menciptakan manusia dan Alam semesta. Maka menjadi kewajiban manusia untuk taat kepadaNya. Bukan sebaliknya, menggambarkan sifat Allah yang kejam dan terkesan menyeramkan di telinga anak usia dini yang belum mampu berpikir abstrak. Seperti perkataan " Awas ya nak kalau kamu tidak sholat nanti Allah marah!"; " Nanti Allah bakar kamu di neraka!"

Setelah menanamkan akidah pada jiwanya, maka motivasi anak untuk beramal sholeh sebagai wujud ketaatan kepada Allah. Jangan sungkan mengungkapkan dalil (Alqur'an dan hadist Nabi SAW) yang menjadi landasan orangtua memerintahkan ini dan itu. Sehingga anak terbiasa memahami bahwa ini adalah perintah yang datangnya dari Allah dan RasulNya. Tanamkan keyakinan bahwa apa yang diperintahkan Allah pasti baik, dan apa yang dilarangNya pasti buruk. Dengan begitu diharapkan anak dapat dengan sukarela dan penuh kesadaran melaksanakan kewajiban dan menjauhi larangan. Bukan karna tuntutan paksaan ayah dan ibunya.

Lakukan repetisi (pengulangan) pijakan dalil untuk perintah, larangan dan adab pada anak usia dini. Orangtua tidak boleh bosan mengingatkan anak. Semisal mengungkapkan hadist "Laa tasrob qaaiman" (jangan minum sambil berdiri), ketika anak melakukan kelalaian minum sambil berdiri. Sementara untuk hal-hal yang mubah seperti main kotor, lari-lari, dan naik tangga, gunakan pilihan kata yang lain, bukan kata negasi. Seperti "Ibu percaya kamu akan berhatihati naik tangga", "Cukup berjalan saja", Jaga kebersihan bajumu, Allah cinta dengan kebersihan" dan pilihan kata yang lain yang mudah dipahami anak.

Lakukan pendampingan yang menyenangkan dalam proses pembiasaan anak beramal sholeh. Sehingga anak tidak akan merasa bahwa kewajiban itu beban. Disinilah peran orangtua menerapkan qaulan layinan, berkata penuh cinta, kelembutan dan motivasi. Tunjukan pula sikap yang menyenangkan dan persuasif agar anak senang beramal sholeh.

Ketika anak sudah berusia tamyiz (sudah mampu membedakan benar dan salah), gambarkan adanya reward dan punishment pada setiap amal yang disepakati antara orangtua dan anak. Ketika orangtua harus menjatuhkan hukuman kepada anak (sesuai kesepakatan), maka yakinkan bahwa itu adalah bagian kasih sayang orangtua kepadanya dengan meluruskan kelalaiannya, agar kelak ia tak dapatkan azab Allah yang lebih berat. Bukan karena kebencian orangtua kepadanya. Di usia ini anak sudah bisa diajak berdiskusi sebagaimana diskusi dua arah antara Nabi Ibrahim AS dengan putranya Nabi Ismail AS.Percakapan antara keduanya menggambarkan kepada kita bahwa Nabi Ibrahim AS adalah ayah yang penyayang, namun ia jujur kepada anaknya ihwal perintah Allah untuk menyembelih dirinya. Sebagai ayah, Nabi Ibrahim tidak otoriter. Diajaknya putra kesayangannya itu untuk bicara dari hati ke hati, dan meminta pendapat Ismail tentang perintah Allah tersebut. Mendengar penuturan ayahnya, Ismail langsung menjawab tanpa berpikir panjang:

"Wahai ayahku, laksanakanlah apa yang telah diperintahkan Allah kepadamu. Engkau akan menemuiku insyaa Allah sebagai orang yang sabar dan patuh kepada perintah..."

\section{Karakter Anak Usia Dini}

Seorang anak memiliki jiwa. Dia dilahirkan dalam keadaan fitrah suci bersih tanpa noda. Maka tabiatnya, seorang anak mudah menerima kebenaran. Jika kemudian saat ini banyak stempel negatif yang diberikan kepada anak, semisal anak nakal, anak susah diatur dan lain sebagainya, berarti ada yang tidak tepat dalam ta'dib dan komunikasi orangtua terhadap anak. Sehingga kesalahan dalam ta'dib dan komunikasi ini berdampak pada rapuhnya karakter anak.

Pembentukan karakter yang baik pada diri anak tidak bisa ditempuh dengan cara yang instan. Diperlukan proses dan kesabaran dalam menjalaninya. Maka mendidik anak adalah pekerjaan hati. Orangtua harus memiliki waktu berkualitas setiap hari untuk anak. Dimana di waktu tersebut orangtua hadir fisik dan juga jiwanya. Waktu dimana orangtua mendampingi anaknya bermain, 
bercanda, belajar dan menceritakan kisahkisah penuh hikmah.

Hal lain yang seringkali luput dari orangtua dalam pendidikan anak, adalah muhasabah diri. Bercermin tentang bagaimana kualitas orangtua dihadapan anak. Apakah orangtua telah cukup pantas menjadi role model ideal bagi anak. Jika orangtua ingin dipatuhi, maka cara paling efektif adalah merubahdiri sendiri terlebih dahulu.

Allah berfirman:

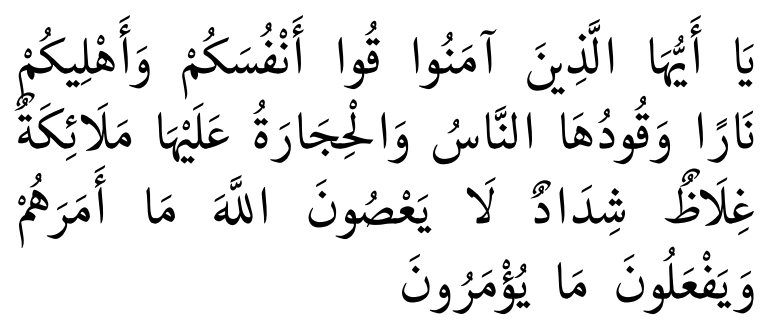

Hai orang-orang yang beriman, peliharalah dirimu dan keluargamu dari api neraka yang bahan bakarnya adalah manusia dan batu; penjaganya malaikat-malaikat yang kasar, keras, dan tidak mendurhakai Allah terhadap apa yang diperintahkan-Nya kepada mereka dan selalu mengerjakan apa yang diperintahkan. (QS. At-Tahrim: 6)

Dalam ayat tersebut Allah memberi penekananan pada lafazh Peliharalah dirimu, selanjutnya keluargamu. Maka tanggungjawab orantua sejatinya adalah memelihara dirinya dan anak-anaknya. Berusaha sungguhsungguh agar berhasil mengantarkan diri dan keluarganya ke jalan yang Allah Ta'ala ridhai dan tidak menjatuhkan mereka dalam kedurhakaan kepada Berikutnya, perkara terpenting dalam agama ini,yaitu do'a. Tiada daya dan upaya kecuali milik Allah Taala. Sebaik apapun ortangtua mendidik anak, namun Allahlah yang menggenggam hati mereka. Hanya Allah sajalah yang Maha mengilmui segala yang Nampak dan tersembunyi pada kehidupan anak-anak di masa yang akan datang. Maka kepada-Nya lah sepatutnya orangtua meminta penjagaan dan perlindungan bagi anak.

\section{Kesimpulan}

Anak adalah amanah. Orangtua bertanggung jawab dalam pendidikan anak dengan membangun karakternya sejak dini. Untuk menunjang keberhasilan orangtua dalam pendidikan anak, dibutuhkan ilmu tentang metode ta'dib islami dan komunikasi Islami. Tadib adalah perpaduan semua unsur pendidikan mulai dari menanamkan pemahaman yang sebelumnya tidak dipahami anak, memunculkan kesadaran untuk beramal, pendampingan, pembiasaan dan pemaksaan dalam tuntutan pelaksanaan kewajiban, hingga hukuman jika terdapat pelanggaran. Sehingga tadib membutuhkan pengajaran dalam aspek kognitif serta perintah/ajakan dan larangan dalam aspek afektif.

Metode komunikasi yang menjadi panduan bagi seorang muslim dalam pendidikan anak ditandai dengan lafaz qaulan didalam Al-Quran. Diantaranya: (1) Qaulan Sadida; (2) Qaulan Baligha; (3) Qaulan Ma'rufa; (4) Qaulan Karima; (5) Qaulan Layina; (6) Qaulan Maisura. Dengan metode ta'dib islami dan komunikasi islami yang tepat disertai doa, Insyaa Allah pembangunan karakter anak usia dini akan lebih mudah dilakukan.

\section{Daftar Pustaka}

Tafsir Ahmad. (1992). Ilmu Pendidikan dalam Perspektif Islam. Jakarta: Remaja Rosda karya

Suyanto. (2005). Konsep Dasar Anak Usia Dini. Jakarta: Departemen Pendidikan Nasional

Rambe, Imron. (2012). Konsep Ta'dib Sebagai Alternatif Pendidikan Islam Menurut Syed M. Naquib Al Attas (http:// syedrambe.blogspot.co.id). Diunduh pada 26 Desember 2017.

Daftar Definisi Komunikasi (http:// Wikipedia. org/wiki) diunduh pada 26 Desember 2017.

Prinsip Komunikasi Islam (http:// www.risalah islam.com) diunduh pada 26 Desember 2017.

Qoulan Sadida dalam Al Qur'an (http:// elSyahida.blogspot.co.id) Diunduh pada 26 Desember 2017. 